\title{
Refractive Outcomes of Femtosecond Laser- assisted Cataract Surgery with Arcuate Keratotomy and Standard Phacoemulsification with Toric Intraocular Lens Implantation
}

\author{
Meng-Yin Lin \\ Taipei Medical University-Shuang Ho Hospital \\ Yun-Dun Shen \\ Taipei Medical University-Shuang Ho Hospital \\ Hsin-Yuan Tan \\ Chang Gung Memorial Hospital \\ l-Jong Wang \\ National Taiwan University Hospital \\ I-Chan Lin ( $\nabla$ ichanlin@gmail.com ) \\ Taipei Medical University
}

\section{Research Article}

Keywords: Arcuate keratotomy, Astigmatism, Femtosecond laser, Toric intraocular lens

Posted Date: January 13th, 2021

DOI: https://doi.org/10.21203/rs.3.rs-142481/v1

License: (c) (i) This work is licensed under a Creative Commons Attribution 4.0 International License.

Read Full License

Version of Record: A version of this preprint was published at International Ophthalmology on November 16th, 2021. See the published version at https://doi.org/10.1007/s10792-021-02090-8. 


\section{Abstract}

Background: Both femtosecond laser-assisted arcuate keratotomy (FS-AK) and toric intraocular lens (IOL) implantation were effective in correction for eyes with corneal astigmatism. The objective of this study was to evaluate the postoperative refractive outcomes of patients receiving femtosecond laser-assisted cataract surgery (FLACS) with FS-AK and patients receiving standard phacoemulsification with toric intraocular lens implantation

Methods: This retrospective study reviewed the postoperative outcome of patients undergoing FLACS with FS-AK (FS-AK group) and patients undergoing standard phacoemulsification with toric IOL implantation (toric IOL group). The main outcome measures were bare and corrected visual acuities, keratometric and refractive astigmatism, and vector analysis.

Results: The FL-AK group included 41 eyes with preoperative keratometric astigmatism of -1.64 diopters (D) \pm 0.42 (standard deviation), and the toric IOL group included 53 eyes with preoperative keratometric astigmatism of $-2.29 \pm 0.91 \mathrm{D}(P<0.001)$. Postoperative refractive astigmatism was comparable between the two groups. Postoperative bare vision was significantly better $(P=0.005)$ and corrected visual acuity was marginally better in the toric IOL group than in the FS-AK group $(P=0.051)$. The absolute angles of error were $9.95 \pm 9.57$ degrees and $5.08 \pm 4.94$ degrees $(P=0.02)$ in the FS-AK and toric IOL groups, respectively.

Conclusion: Both FLACS with FS-AK and standard phacoemulsification with toric IOL implantation represent safe and effective methods for astigmatism correction at the time of cataract surgery. Standard phacoemulsification with toric IOL implantation achieves better visual outcome than combined FLACS and FS-AK at 6-month follow up.

\section{Background}

Cataract surgery was considered a refractive surgery in the past few years. An increasing number of patients started demanding for better visual quality rather than just a safe cataract surgery. Postoperative residual astigmatism is one of the leading causes of ordinary visual outcomes and poor patient satisfaction [1]. The incidence of preoperative corneal astigmatism was estimated to be $87 \%$, and $22.2 \%$ of them were $\geq 1.50 \mathrm{D}$ [2]. Therefore, simultaneous astigmatism correction during cataract surgery is a major trend in modern cataract surgery. Various techniques have been employed to manage corneal astigmatism during cataract surgery, including limbal relaxing incision, peripheral corneal incision, and toric intraocular lens (IOL) implantation [3, 4]. With advances in femtosecond laser technology, femtosecond laser-assisted arcuate keratotomy (FS-AK) was adopted to correct astigmatism [5].

Femtosecond laser provides superior accuracy and predictability in customized corneal cutting compared with the traditional manual technique [6, 7]. Even in correcting high postkeratoplasty astigmatism, FS-AK has displayed better alignment outcomes than mechanized arcuate keratotomy (AK) [8, 9]. Ruckl et al. reported the initial results of FS-AK in treating corneal astigmatism before a planned cataract surgery [10], 
which revealed a significant improvement in manifest cylinder, topographic cylinder, and bare vision. Furthermore, Chan et al. reported the stability and efficacy of penetrating FS-AK after 2 years of surgery [11]. Phacoemulsification with a toric IOL has been widely used to correct corneal astigmatism and has been effective and safe in various toric IOL models $[12,13]$. The main concern regarding toric IOL implantation is potential postoperative IOL rotation and misalignment.

Yoo et al. compared the refractive outcome of patients receiving FS-AK after standard phacoemulsification and patients receiving simultaneously standard phacoemulsification and toric IOL implantation, and they found comparable results between the two methods [14]. However, data comparing the refractive outcomes of patients receiving femtosecond laser-assisted cataract surgery (FLACS) with FS-AK and patients receiving standard phacoemulsification with toric IOL implantation are insufficient. The aim of the present study was to compare the refractive outcomes of these two different methods in correcting low to moderate regular astigmatism in cataract surgery.

\section{Methods}

This retrospective study reviewed case-records at the Department of Ophthalmology, Shuang Ho hospital, Taiwan. Between October 2015 and December 2016, patients with cataract and coexisting corneal astigmatism between -1.5 and $-4.5 \mathrm{D}$ were recommended simultaneous cataract surgery and astigmatism correction. We divided patients into two groups: one group received FLACS with FS-AK, and the other group received standard phacoemulsification with toric IOL implantation.As age and astigmatism type affect accuracy in predicting the outcomes of FS-AK [15], we selected age- and astigmatism type-matched patients who underwent standard phacoemulsification with toric IOL implantation during the same study period in the toric IOL group. The Joint Institutional Review Board Committee of Taipei Medical University approved the study protocol. The study was conducted in accordance with the tenets of the Declaration of Helsinki. All patients underwent a thorough preoperative ophthalmologic assessment, including manifest refraction, best uncorrected visual acuities (UCVA) and best-corrected distant visual acuities (BCVA), noncontact tonometry (NT530P, NIDEK, Gamagori, Japan), slit-lamp, fundus examination, automated keratometry (KR-8900, Topcon, Tokyo, Japan), axial length, biometry (IOLMaster; Carl Zeiss Meditec Inc, Dublin, California, USA), and corneal topography (Keratograph 4; Oculus, Washington, USA). With different postoperative target refraction, the best UCVA was defined as the best uncorrected distance, intermediate or near vision. Patients with severe corneal disorders, irregular astigmatism, subcapsular opacity of the crystalline lens, active ophthalmic disease, anterior or posterior segment disease were excluded.

\section{Surgical techniques}

All surgeries were performed by a single surgeon (Y.D.S.) under topical anesthesia with $0.5 \%$ proparacaine hydrochloride (Alcon Laboratories Inc, Fort Worth, Texas, USA). 
In the FS-AK group, patients were examined before the surgery with head fixed and chin rested on the slit lamp, and two points at 3 and 9 o'clock were marked on the limbus when the patient was sitting upright. Patients were then transferred to a femtosecond laser platform (LENSAR, Orlando, Florida). A pair of AK incisions were placed in the steep meridian, which was determined using a topographic map. The incision depth of AK extended from $100 \mathrm{~m}$ above the endothelium to the surface of the epithelium with a 90 degrees side-cut angle. The optical zone diameter was set at $8 \mathrm{~mm}$. The range of angular arc length of AK incision was between 30 degrees and 80 degrees according to the surgeon's nomogram, which was modified from the December 2011 version of Woodcock LenSx astigmatic nomogram [16]. The suction ring was docked on the patient's eye and was centered on the pupil center mark. A femtosecond laser was then used to create anterior capsulotomy, lens fragmentation, and AK consecutively. After removal of the docking cone and suction ring, the main incision for phacoemulsification was created at 210 degrees in the right eye and 30 degrees in the left eye by using a 2.2-mm disposable blade (Alcon, Laboratories, Inc., Fort Worth, TX, USA). A paracentesis was created using a microvitreoretinal blade (Alcon, Laboratories, Inc.) 60 degrees apart from the main corneal incision. Phacoemulsification and implantation of a foldable aspheric IOL (TECNIS, Abbott Medical Optics, Inc., Santa Ana, CA, USA) were then performed. At the end of surgery, the pair of keratotomies were dissected with a blunt spatula to ensure full separation of the incisions.

In the toric IOL group, the IOL power and alignment axis were calculated using an online calculator website (https://www.raytrace.rayner.com).Surgically induced astigmatism (SIA) of the main corneal incision was set as $0.25 \mathrm{D}$. Furthermore, the steep corneal meridian was determined through topography and marked by the surgeon with Neuhann one-step toric marker (ASICO, Illinois, USA) while patients were sitting upright. The main incision and paracentesis were created at the same locations as in the FS-AK group by using a 2.2-mm disposable blade and microvitreoretinal blade, respectively (Alcon Laboratories, Inc.). Standard phacoemulsification was performed using a foldable IOL (T-flex aspheric Toric; Rayner, UK) implanted into the capsular bag through a Monarch II injector with a C-cartridge (Alcon Laboratories, Inc.). Using a residual ophthalmic viscoelastic device, the corrected IOL alignment was verified at the end of surgery. Stromal hydration of the main incision was performed to form an anterior chamber.

Postoperatively, topical eye drops of tobradex suspension, which contained $0.1 \%$ dexamethasone and $0.3 \%$ tobramycin (Alcon Laboratories Inc.), were prescribed four times a day for 1 month. Postoperative examinations were performed at 1 day, 1 week, 1 month, 3 months, and 6 months after surgery.

Postoperative examinations included manifest refraction, UCVA, BCVA, noncontact tonometry, automated keratometry, and topography.

\section{Vector analysis}

The astigmatic analysis was performed using the Alpins method [17] to evaluate the effective correction of astigmatism. The target-induced astigmatism (TIA) vector is the planned surgically induced astigmatic change after surgery, which is equivalent to preoperative corneal astigmatism. SIA is the actual surgically 
induced astigmatic change. The difference vector (DV) is the induced astigmatic change that would enable the initial surgery to achieve its intended goal, which is equivalent to postoperative astigmatism. The magnitude of error (ME) is the arithmetic difference between SIA and TIA. The angle of error (AE) is the angle described by vectors of SIA versus TIA. The correction index $(\mathrm{CI})$ is calculated as the ratio of SIA to TIA. It indicates overcorrection if it is $>1$ and undercorrection if it is $<1$. The index of success (IOS) is the ratio of DV to TIA (the ideal value is 0 ). The flattening index $(\mathrm{FI})$ is the proportion of SIA required to reduce astigmatism at the intended meridian. SAS 9.3 (Cary, NC, USA) was used to perform statistical analyses. A paired $t$ test was used to compare preoperative and postoperative continuous variables. An independent sample $t$ test or Fisher's exact test were used to compare the data between two groups. $P<$ 0.05 was considered statistically significant.

\section{Results}

During a 15-month study period, combined FLACS and FS-AK were performed in 41 eyes of 36 patients, and standard phacoemulsification with toric IOL implantation was done in 53 eyes of 47 patients. The preoperative age were $67.0 \pm 13.3$ and $67.2 \pm 11.4$ years $(P=0.92)$, axial lengths were $24.3 \pm 2.0 \mathrm{~mm}$ and $24.6 \pm 2.2 \mathrm{~mm}(P=0.47)$, and against-the-rule astigmatism were $79.3 \%$ and $61.1 \%(P=0.18)$ in the FS-AK and the toric IOL groups, respectively (Table 1). The preoperative UCVA and BCVA (logarithm of the minimum angle of resolution) were not significantly different between the two groups. Postoperative UCVA was $0.25 \pm 0.32$ versus $0.12 \pm 0.11(P=0.005)$ and postoperative BCVA was $0.16 \pm 0.17$ versus 0.08 $\pm 0.09(P=0.051)$ in the FS-AK and the toric IOL groups, respectively, at 6 months after surgery. This finding implies that postoperative UCVA was significantly better and BCVA was marginally better in the toric IOL group than in the FS-AK group. The values of the mean preoperative refractive astigmatism were $-2.33 \pm 1.43 \mathrm{D}$ and $-3.44 \pm 1.72 \mathrm{D}(P=0.005)$, mean preoperative corneal astigmatism were $-1.64 \pm 0.42$ $\mathrm{D}$ and $-2.29 \pm 0.91 \mathrm{D}(P<0.001)$, mean postoperative refractive astigmatism were $-0.98 \pm 0.61 \mathrm{D}$ and $0.92 \pm 0.72 \mathrm{D}(P=0.41)$, and mean postoperative corneal astigmatism were $-0.69 \pm 0.51 \mathrm{D}$ and $-2.41 \pm$ $0.89 \mathrm{D}(P<0.001)$ in the FS-AK and the toric IOL group, respectively, at 6 months after surgery (Table 2$)$. Our results showed comparable postoperative refractive astigmatism at 1 month follow-up and 6 months follow-up between these two groups. A postoperative reduction in corneal astigmatism was observed in the FS-AK group, but no significant reduction in corneal astigmatism was observed in the toric IOL group. Undercorrection was noted in $76.5 \%$ and $79.2 \%$ of the eyes in the FS-AK and the toric IOL groups, respectively. 
Table 1

Baseline parameters of the FS-AK and the toric IOL groups

\begin{tabular}{|llll|}
\hline Variable & FS-AK & Toric IOL & Pvalue $^{*}$ \\
\hline Number of eyes(n) & 41 & 53 & - \\
\hline Age (years) & $67.0 \pm 13.3$ & $67.2 \pm 11.4$ & 0.917 \\
\hline Axial length (mm) & $24.3 \pm 2.0$ & $24.6 \pm 2.2$ & 0.471 \\
\hline Astigmatism type & & 0.177 \\
\hline With-the-rule(n) & $1(3.4 \%)$ & $2(3.7 \%)$ & \\
\hline Oblique(n) & $5(17.2 \%)$ & $19(35.2 \%)$ & \\
\hline Against-the-rule(n) & $23(79.3 \%)$ & $33(61.1 \%)$ & \\
\hline aFS-AK: femtosecond laser-assisted arcuate keratotomy & \\
\hline bIOL: intraocular lens. Data are presented as mean \pm standard deviation \\
\hline *Independent sample t-test or Fisher's exact test \\
\hline
\end{tabular}


Table 2

Changes in visual acuities, astigmatism, and keratometry of the FS-AK and the toric IOL groups

\begin{tabular}{|llll|}
\hline Parameter & FS-AK & Toric IOL & Pvalue \\
\hline UCVA (logMAR) & & & \\
\hline Preoperative & $0.92 \pm 0.41$ & $0.67 \pm 0.52$ & 0.206 \\
\hline Postop 1 month & $0.23 \pm 0.23$ & $0.13 \pm 0.12$ & 0.053 \\
\hline Postop 6 months & $0.25 \pm 0.32$ & $0.12 \pm 0.11$ & 0.005 \\
\hline BCVA (logMAR) & & & \\
\hline Preoperative & $0.57 \pm 0.26$ & $0.54 \pm 0.33$ & 0.658 \\
\hline Postoperative 1 month & $0.17 \pm 0.16$ & $0.09 \pm 0.10$ & 0.009 \\
\hline Postoperative 6 months & $0.16 \pm 0.17$ & $0.08 \pm 0.09$ & 0.051 \\
\hline Refractive cyclinder (D) & & & \\
\hline Preoperative & $-2.33 \pm 1.43$ & $-3.44 \pm 1.72$ & 0.005 \\
\hline Postoperative 1 month & $-1.00 \pm 0.56$ & $-0.88 \pm 0.53$ & 0.322 \\
\hline Postoperative 6 months & $-0.98 \pm 0.61$ & $-0.92 \pm 0.72$ & 0.405 \\
\hline Keratometric cylinder (D) & & & \\
\hline preoperative & $-1.64 \pm 0.42$ & $-2.29 \pm 0.91$ & $<0.001$ \\
\hline Postoperative 1 month & $-0.67 \pm 0.43$ & $-2.13 \pm 0.97$ & $<0.001$ \\
\hline Postoperative 6 months & $-0.69 \pm 0.51$ & $-2.41 \pm 0.89$ & $<0.001$ \\
\hline Mean corneal keratometry (D) & $43.1 \pm 1.5$ & $45.1 \pm 1.6$ & 0.005 \\
\hline Preoperative & $43.5 \pm 1.5$ & $44.9 \pm 1.4$ & 0.004 \\
\hline Postoperative 1 month & & $45.5 \pm 1.6$ & \\
\hline Postoperative 6 months & & & \\
\hline (D) & & & \\
\hline
\end{tabular}

All values are mean \pm SD

FS-AK: femtosecond laser-assisted arcuate keratotomy, IOL: intraocular lens, VA: best-corrected visual acuity, UCVA: uncorrected visual acuity, logMAR: logarithm of the minimum angle of resolution, SD: standard deviation, $\mathrm{Cl}$ : confidence interval, D: diopters

*Independent sample t-test

Table 3 shows the outcomes of the refractive vector analysis. TIAs were $2.26 \pm 1.21$ and $3.31 \pm 1.69 \mathrm{D}$ in the FS-AK and the toric IOL groups, respectively $(P=0.005)$. SIAs were $1.78 \pm 1.34 \mathrm{D}$ and $3.02 \pm 1.64 \mathrm{D}$ in the FS-AK and the toric IOL groups, respectively $(P=0.001)$. The difference of mean AE between two 
groups was not statistically significant $(P=0.12)$, which indicates that the average achieved correction axis was close to the intended axis. However, the absolute AEs were $9.95 \pm 9.57$ degrees and $5.08 \pm 4.94$ degrees in the FS-AK and the toric IOL groups $(P=0.02)$, respectively, which indicates that the alignment of the toric IOL group was better than that of the FS-AK group. MEs were $-0.50 \pm 0.83 \mathrm{D}$ and $-0.30 \pm 0.89$ $\mathrm{D}$ in the FS-AK and the toric IOL groups, respectively $(P=0.31)$, indicating undercorrection in both groups.

Table 3

Refractive vector analysis of the FS-AK and the toric IOL groups

\begin{tabular}{|llll|}
\hline Parameter & FS-AK & Toric IOL & Pvalue $^{*}$ \\
\hline SIA (D) & $1.78 \pm 1.34$ & $3.02 \pm 1.64$ & 0.001 \\
\hline SIA axis (degree) & $92.70 \pm 35.62$ & $99.96 \pm 48.03$ & 0.489 \\
\hline TIA (D) & $2.26 \pm 1.21$ & $3.31 \pm 1.69$ & 0.005 \\
\hline TIA axis (degree) & $99.44 \pm 32.94$ & $99.44 \pm 32.94$ & 0.900 \\
\hline AE (degrees) & $3.76 \pm 13.28$ & $1.37 \pm 6.95$ & 0.382 \\
\hline Absolute AE (degree) & $9.95 \pm 9.57$ & $5.08 \pm 4.94$ & 0.016 \\
\hline ME (D) & $-0.50 \pm 0.83$ & $-0.30 \pm 0.89$ & 0.310 \\
\hline Radians & $-0.23 \pm 1.01$ & $0.01 \pm 0.35$ & 0.116 \\
\hline FI & $0.67 \pm 0.63$ & $0.67 \pm 0.63$ & 0.026 \\
\hline Correction Index & $0.87 \pm 0.60$ & $0.97 \pm 0.37$ & 0.342 \\
\hline DV (D) & $1.09 \pm 0.66$ & $1.03 \pm 0.65$ & 0.696 \\
\hline DV axis(degree) & $88.26 \pm 43.60$ & $81.91 \pm 46.67$ & 0.557 \\
\hline IOS & $0.66 \pm 0.62$ & $0.41 \pm 0.52$ & 0.062 \\
\hline All values are mean \pm SD & & & \\
\hline $\begin{array}{l}\text { FS-AK: femtosecond laser-assisted arcuate keratotomy, IOL: intraocular lens, SIA: surgically induced } \\
\text { astigmatism, TIA: target-induced astigmatism, AE: angle of error, ME: } \text { magnitude of error, Fl: flattening } \\
\text { index, DV: difference vector, IOS: index of success, D: diopter, SD: standard deviation, Cl: confidence } \\
\text { interval }\end{array}$ & & & \\
\hline *Independent sample t-test & & & \\
\hline
\end{tabular}

Table 4 shows the results of the keratometric vector analysis. The absolute AE was $10.70 \pm 10.23$ degrees in the FS-AK group. Cls were $0.65 \pm 0.35$ and $0.35 \pm 0.47(P=0.007)$, IOSs were $0.44 \pm 0.42$ and $1.01 \pm 0.29$ $(P<0.001)$, and Fls were $0.45 \pm 0.41$ and $0.15 \pm 0.48(P=0.006)$ in the FS-AK and the toric IOL groups, respectively. No cases of corneal perforation or epithelial ingrowth were detected during the study period. 
Table 4

Keratometric vector analysis of the FS-AK and the toric IOL groups

\begin{tabular}{|llll|}
\hline Parameter & FS-AK & Toric IOL & Pvalue \\
\hline SIA (D) & $1.10 \pm 0.61$ & $0.70 \pm 0.85$ & 0.034 \\
\hline SIA axis(degree) & $0.50 \pm 0.67$ & $105.36 \pm 42.89$ & $<0.001$ \\
\hline TIA (D) & $1.55 \pm 0.88$ & $2.31 \pm 0.94$ & 0.001 \\
\hline TIA axis(degree) & $105.54 \pm 38.01$ & $106.02 \pm 47.39$ & 0.964 \\
\hline AE (degree) & $6.43 \pm 50.74$ & $-0.67 \pm 44.98$ & 0.518 \\
\hline Absolute AE (degree) & $10.70 \pm 10.23$ & $30.88 \pm 33.12$ & 0.006 \\
\hline ME (D) & $-0.23 \pm 0.72$ & $-1.61 \pm 1.24$ & $<0.001$ \\
\hline Radians & $-0.13 \pm 0.39$ & $-0.02 \pm 1.57$ & 0.693 \\
\hline FI & $0.45 \pm 0.41$ & $0.15 \pm 0.48$ & 0.006 \\
\hline Correction Index & $0.65 \pm 0.35$ & $0.35 \pm 0.47$ & 0.007 \\
\hline DV (D) & $0.69 \pm 0.49$ & $2.26 \pm 0.99$ & $<0.001$ \\
\hline DV axis(degree) & $100.65 \pm 51.15$ & $92.62 \pm 47.89$ & 0.515 \\
\hline IOS & $0.44 \pm 0.42$ & $1.01 \pm 0.29$ & $<0.001$ \\
\hline All values are mean \pm SD & & & \\
\hline $\begin{array}{l}\text { FS-AK: femtosecond laser-assisted arcuate keratotomy, IOL: intraocular lens, SIA: surgically induced } \\
\text { astigmatism, TIA: target-induced astigmatism, AE: angle of error, ME: } \text { magnitude of error, FI: flattening } \\
\text { index, DV: difference vector, IOS: index of success, D: diopter, SD: standard deviation, Cl: confidence } \\
\text { interval }\end{array}$ & & & \\
\hline *Independent sample t-test & & & \\
\hline
\end{tabular}

Figure 1 shows the double-angle plot of refractive astigmatism in the FS-AK group. In the FS-AK group, the mean values of preoperative and postoperative refractive astigmatism were $-2.33 \pm 1.43 \mathrm{D}$ and $0.98 \pm 0.61 \mathrm{D}$, respectively $(P<0.001)$. Figure 2 shows the double-angle plot of refractive astigmatism in the toric IOL group. In the toric IOL group, the mean values of preoperative and postoperative refractive astigmatism were $-3.44 \pm 1.72 \mathrm{D}$ and $-0.92 \pm 0.72 \mathrm{D}$, respectively $(P<0.001)$. In both methods, compared with preoperative dots, postoperative astigmatism dots were distributed closer to null points, and standard deviations were decreased.

\section{Discussion}

This study showed the difference of postoperative astigmatism values between the FS-AK group and the toric group was not statistically significant. The outcome of UCVA was significantly better $(P=0.01)$ and 
that of BCVA was marginally better $(P=0.051)$ in the toric IOL group than in the FS-AK group 6 months after surgery. Our study is the first study to compare the refractive outcomes of patients receiving combined FLACS and FLAK and patients receiving standard phacoemulsification and toric IOL implantation. Yoo et al. compared the refractive outcomes of patients who underwent FS-AK for after standard phacoemulsification and patients who underwent standard phacoemulsification and toric IOL implantation. They observed that FS-AK was effective and comparable to toric IOL implantation in correcting postoperative refractive astigmatism and improving visual acuities at 5 months after surgery. Moreover, they demonstrated that AE was not significantly different between the two methods, whereas the data of absolute AE were not shown [14]. Our study result is similar to the study conducted by Yoo et al, and supported both FS-AK and toric IOL are effective surgical methods in astigmatism correction.

Alignment is a crucial factor to determine the success of astigmatism correction. In previous studies, FSAK appeared to induce more absolute AE than toric IOL implantation. In a study of FLACS with penetrating FS-AK, the absolute AE was $14.0 \pm 15.5$ degrees after 2 years of follow-up [11]. Hoffart et al. conducted a randomized controlled study comparing penetrating FS-AK with manual AK for correcting postkeratoplasty astigmatism [8], where keratometric absolute AE of FS-AK was $11.67 \pm 17.95$ degrees. Regarding Rayner T-flex toric IOL, the rotation of IOL has been reported to be 3.4 degrees [18] and $5.54 \pm$ 4.65 degrees [19]. In the current study, we observed a significantly higher refractive absolute AE with greater deviation in the FS-AK group than in the toric IOL group $(P=0.03)$, which suggests more induced misalignment in the FS-AK group than in the toric IOL group. Increased misalignment consequently resulted in relatively unfavorable outcomes in FI, IOS, UCVA, and BCVA in the FS-AK group compared with the toric IOL group.

Although femtosecond laser has the potential for more consistent corneal incision depth and arc length than manual blade AKs [20], FS-AK still exhibited higher misalignment relative to toric IOL implantation. This misalignment might be related to variations in interpersonal wound healing and nomograms, which needs refinement with large sample sizes specific for penetrating or intrastromal FS-AK. A study on the wound healing process of penetrating FS-AK corneal incisions revealed that epithelial ingrowth inside the wound was noted initially, and then, fibrotic scarring developed consequentially [9], which might lead to an uncertainty of postoperative refractive outcome. Although we dissected to ensure full separation of incisions, wound healing might vary among individuals. Day et al. reported the nomogram for intrastromal FS-AK, wherein they observed that corneal biomechanical parameters were an independent predictor of FS-AK efficacy even after adjusting for AK arc length, AK start depth, and preoperative corneal cylinder [15]. Additionally, penetrating or intrastromal incisions and diameter of incisions might also affect results. Therefore, incorporation of individualized biomechanical parameters to create a customized treatment protocol and nomogram may enhance the precision of astigmatism correction in FS-AK technique.

Numerous studies have investigated the visual outcomes of FLACS and conventional phacoemulsification cataract surgery. A Cochrane review of 16 randomized controlled trials found little evidence of any crucial difference in postoperative visual acuity between FLACS and standard 
phacoemulsification. A meta-analysis of 14567 eyes, 15 randomized controlled trials, and 22 observational cohort studies found no statistically significant difference in UCVA, BCVA, and mean absolute error between the two cohorts of FLACS and manual cataract surgery [21]. Therefore, we speculate that the difference in visual outcomes of the current study may be attributed to the superior alignment of toric IOL compared with FS-AK, regardless of the cataract extraction method.

During cataract surgery, toric IOL implantation has inherent advantages over FS-AK. Toric IOL implantation is less surgically demanding, does not require special instruments, and does not increase the duration of phacoemulsification surgery [22]. Furthermore, cataract surgery does not require additional corneal incisions as FS-AK, which contributes to increased postoperative high-order aberrations $[11,23,24]$ and weakening of the corneal structure. Nevertheless, according to the current study, FS-AK provides efficacious and stable visual improvement even 6 months after surgery and could be an effective procedure for correcting residual astigmatism after cataract surgery or keratoplasty.

This study has some limitations. First, the sample size was small. Second, we neglected the SIA of main incisions in designing FS-AK incisions. Third, the incision depth was not proportional to the entire corneal thickness, which might have led to a outcome that deviated from the expected outcome. Fourth, the planned astigmatism correction in the current study was based on the measurement of anterior corneal astigmatism only, which might have led to overcorrection in eyes that have with-the-rule astigmatism and undercorrection in eyes that have against-the-rule astigmatism [25].

\section{Conclusions}

Both FLACS with FS-AK and standard phacoemulsification with toric IOL implantation were effective in correction for eyes with pre-existing corneal astigmatism. The 6- month outcomes found in this study support that standard phacoemulsification with toric IOL implantation achieves better visual outcomes than FLACS with FS-AK.

\section{Declarations}

\section{Ethics approval and consent to participate}

The Joint Institutional Review Board Committee of Taipei Medical University approved the study protocol (TMU-JIRB N201802025). The study was conducted in accordance with the tenets of the Declaration of Helsinki. The informed consent was obtained from all participants. All of the participants over 18 years of age.

\section{Consent for publication}

Not applicable 


\section{Availability of data and materials}

The datasets used and/or analysed during the current study are available from the corresponding author on reasonable request.

\section{Competing interests}

All authors have read and approved the final manuscript and do not have any financial interest. The authors declare that they have no competing or proprietary interests.

\section{Funding}

This study did not receive any funding.

\section{Authors' contributions}

LMY performed data collection. LMY, HYT, and LIC conceived and drafted the manuscript. LMY, SYD, HYT, WIJ and LIC contributed to the study design. LMY performed the statistical analysis and LIC contributed to data interpretation. All authors have read and approved the final manuscript

\section{Acknowledgements}

Not applicable

\section{References}

1. Gibbons A, Ali TK, Waren DP, Donaldson KE. Causes and correction of dissatisfaction after implantation of presbyopia-correcting intraocular lenses. Clin Ophthalmol. 2016;10:1965-70.

2. Ferrer-Blasco T, Montes-Mico R, Peixoto-de-Matos SC, González-Méijome JM, Cerviño A. Prevalence of corneal astigmatism before cataract surgery. J Cataract Refract Surg. 2009;35:70-5.

3. Poll JT, Wang L, Koch DD, Weikert MP. Correction of astigmatism during cataract surgery: toric intraocular lens compared to peripheral corneal relaxing incisions. J Refract Surg. 2011;27:165-71.

4. Eliwa TF, Abdellatif MK, Hamza II. Effect of limbal relaxing incisions on corneal aberrations. J Refract Surg. 2016;32:156-62.

5. Kymionis GD, Yoo SH, Ide T, Culbertson WW. Femtosecond-assisted astigmatic keratotomy for postkeratoplasty irregular astigmatism. J Cataract Refract Surg. 2009;35:11-13.

6. Khoramnia R, Salgado JP, Lohmann CP, Kobuch KA, von Mohrenfels CW. Precision, morphology, and histology of corneal flap cuts using a 200-kHz femtosecond laser. Eur J Ophthalmol. 2012;22:161-7. 
7. Santhiago MR, Kara-Junior N, Waring GO 4th. Microkeratome versus femtosecond flaps: accuracy and complications. Curr Opin Ophthalmol. 2014;25:270-4.

8. Hoffart L, Proust H, Matonti F, Conrath J, Ridings B. Correction of postkeratoplasty astigmatism by femtosecond laser compared with mechanized astigmatic keratotomy. Am J Ophthalmol. 2009;147:779-87, 787.e771.

9. Nubile M, Carpineto P, Lanzini M, Calienno R, Agnifili L, Ciancaglini M, et al. Femtosecond laser arcuate keratotomy for the correction of high astigmatism after keratoplasty. Ophthalmology. 2009;116:1083-92.

10. Ruckl T, Dexl AK, Bachernegg A, Reischl V, Riha W, Ruckhofer J, et al. Femtosecond laser-assisted intrastromal arcuate keratotomy to reduce corneal astigmatism. J Cataract Refract Surg. 2013;39:528-38.

11. Chan TC, Ng AL, Cheng GP, Wang Z, Woo VCP, Jhanji V. Corneal astigmatism and aberrations after combined femtosecond-assisted phacoemulsification and arcuate keratotomy: two-year results. Am J Ophthalmol. 2016;170:83-90.

12. Holland E, Lane S, Horn JD, Ernest P, Arleo R, Miller KM. The AcrySof Toric intraocular lens in subjects with cataracts and corneal astigmatism: a randomized, subject-masked, parallel-group, 1-year study. Ophthalmology. 2010;117:2104-11.

13. Waltz KL, Featherstone K, Tsai L, Trentacost D. Clinical outcomes of TECNIS toric intraocular lens implantation after cataract removal in patients with corneal astigmatism. Ophthalmology. 2015;122:39-47.

14. Yoo A, Yun S, Kim JY, Kim MJ, Tchah H. Femtosecond laser-assisted arcuate keratotomy versus toric IOL implantation for correcting astigmatism. J Refract Surg. 2015;31:574-78.

15. Day AC, Stevens JD. Predictors of femtosecond laser intrastromal astigmatic keratotomy efficacy for astigmatism management in cataract surgery. J Cataract Refract Surg. 2016;42:251-7.

16. Blehm C, Potvin R. Pseudophakic astigmatism reduction with femtosecond laser-assisted corneal arcuate incisions: a pilot study. Clin Ophthalmol. 2017;11:201-7.

17. Alpins N. Astigmatism analysis by the Alpins method. J Cataract Refract Surg. 2001;27:31-49.

18. Entabi M, Harman F, Lee N, Bloom PA. Injectable 1-piece hydrophilic acrylic toric intraocular lens for cataract surgery: efficacy and stability. J Cataract Refract Surg. 2011; 37: 235-40.

19. Stewart CM, McAlister JC. Comparison of grafted and non-grafted patients with corneal astigmatism undergoing cataract extraction with a toric intraocular lens implant. Clin Exp Ophthalmol. 2010;38:747-57.

20. Gray B, Huang LC, Hill J, Salvador-Silva M, Gwon A, Binder P. Comparison of postoperative wound healing following penetrating or intrastromal corneal arcuate incisions in rabbit eyes performed with a diamond blade or femtosecond laser. Invest Ophthalmol Vis Sci. 2012;53:3529.

21. Popovic M, Campos-Moller X, Schlenker MB, Ahmed IIK. Efficacy and safety of femtosecond laserassisted cataract surgery compared with manual cataract surgery: a meta-analysis of 14567 eyes. Ophthalmology. 2016;123:2113-26. 
22. Titiyal JS, Khatik M, Sharma N, Sehra SV, Maharana PK, Ghatak U, et al. Toric intraocular lens implantation versus astigmatic keratotomy to correct astigmatism during phacoemulsification. $\mathrm{J}$ Cataract Refract Surg. 2014;40:741-7.

23. Kumar NL, Kaiserman I, Shehadeh-Mashor R, Sansanayudh W, Ritenour R, Rootman DS. IntraLaseenabled astigmatic keratotomy for post-keratoplasty astigmatism: on-axis vector analysis. Ophthalmology. 2010;117:1228-35.e1221.

24. Bahar I, Levinger E, Kaiserman I, Sansanayudh W, Rootman DS. IntraLase-enabled astigmatic keratotomy for postkeratoplasty astigmatism. Am J Ophthalmol. 2008;146:897-904.e891.

25. Koch DD, Ali SF, Weikert MP, Shirayama M, Jenkins R, Wang L. Contribution of posterior corneal astigmatism to total corneal astigmatism. J Cataract Refract Surg. 2012;38:2080-7.

\section{Figures}




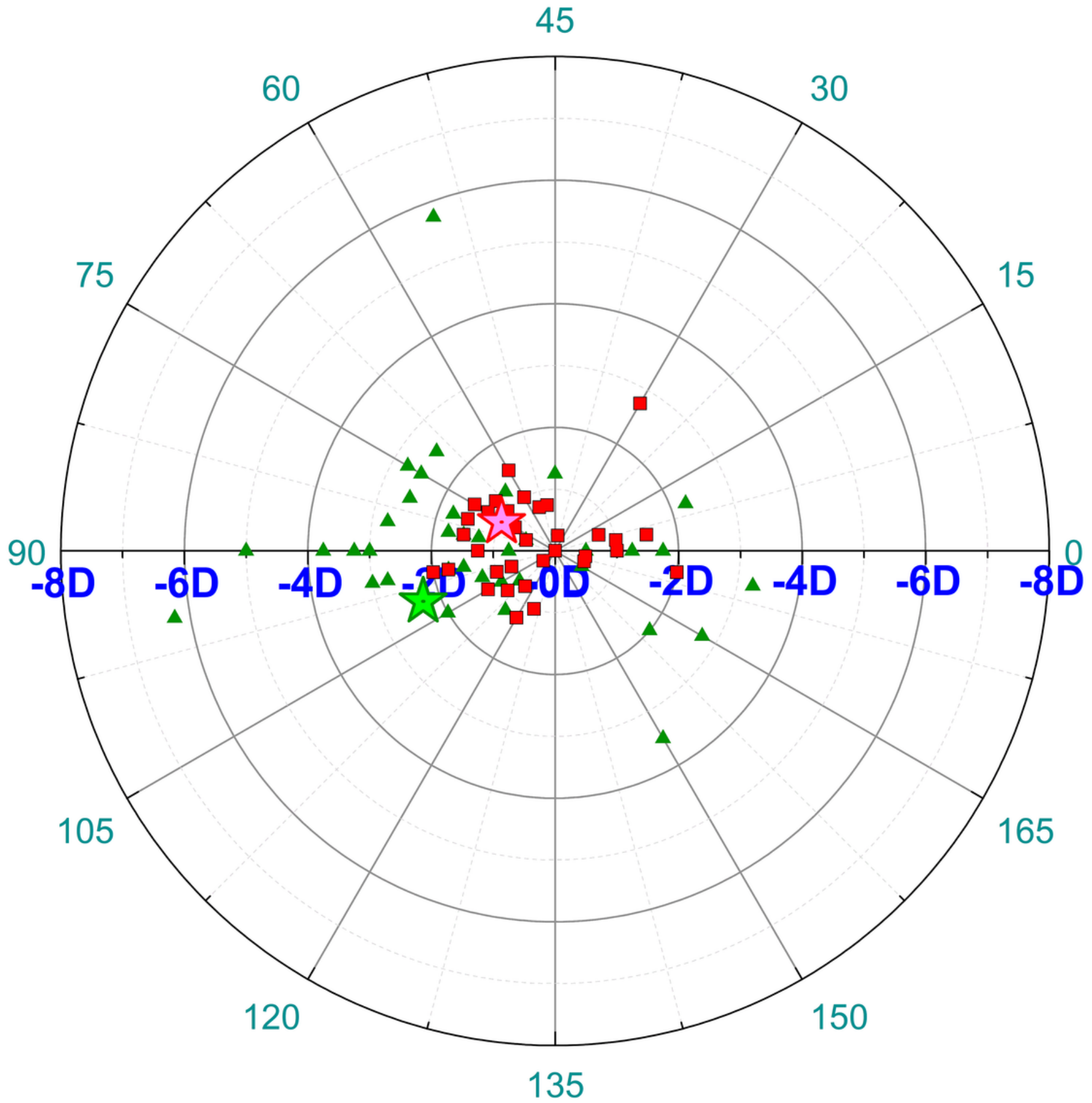

Figure 1

Double-angle plot of refractive astigmatism before $(\Delta)$ and after ( $\square$ ) FLACS) with FS-AK. The green $\Delta$ represents preoperative refractive astigmatism. The green star represents the mean preoperative astigmatism vector $(-2.33 \pm 1.2 \mathrm{D})$. The red $\square$ represents postoperative refractive astigmatism. The pink star represents the mean postoperative astigmatism vector $(-0.98 \pm 0.61 \mathrm{D} ; \mathrm{P}<0.001)$. The mean astigmatism vector is brought closer to the null position after surgery, and the standard deviation is reduced. 


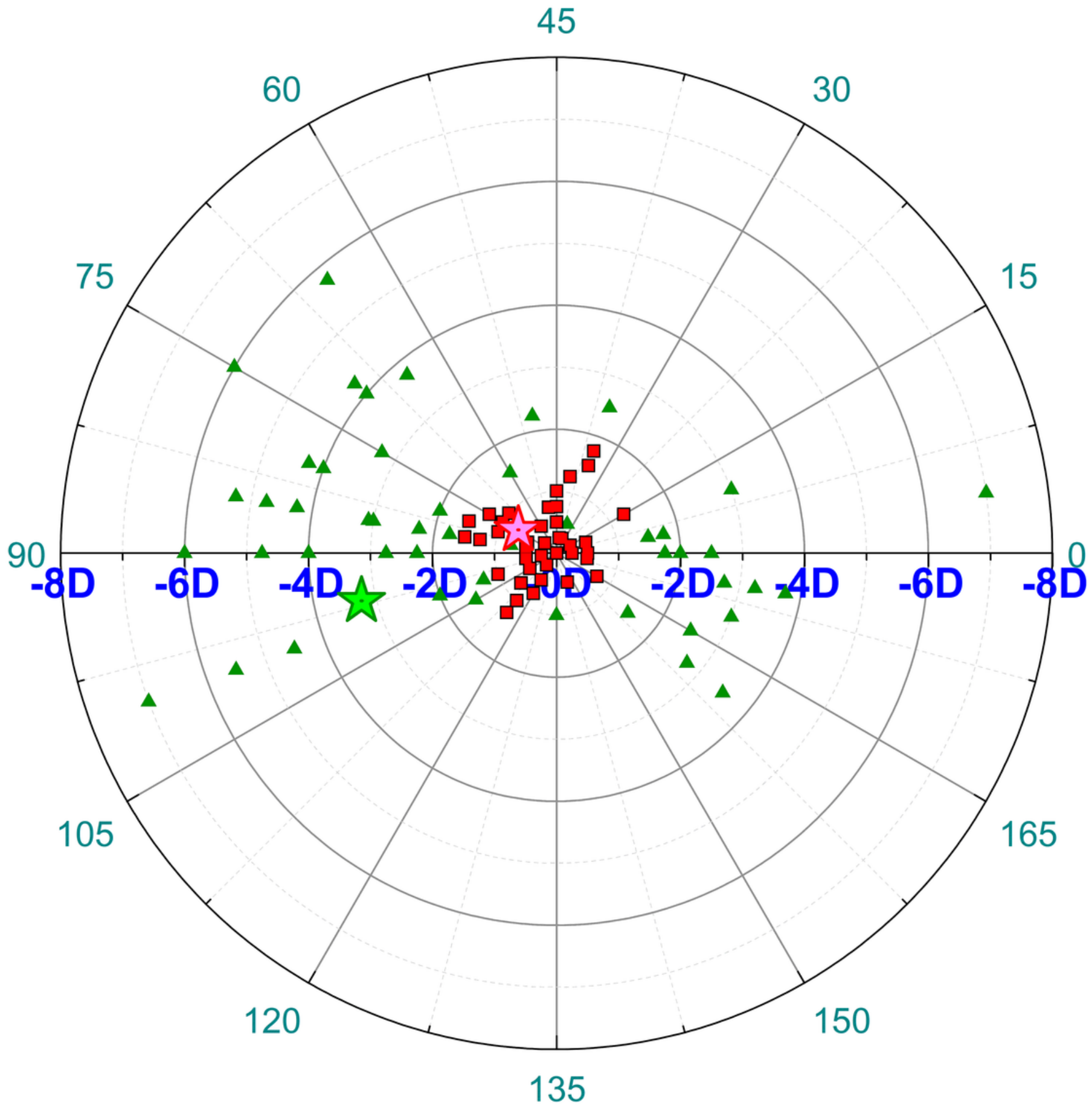

Figure 2

Double-angle plot of refractive astigmatism before $(\Delta)$ and after $(\square)$ standard phacoemulsification with toric IOL implantation. The green $\Delta$ represents preoperative refractive astigmatism. The green $\Delta$ represents the mean preoperative astigmatism vector $(-3.44 \pm 1.72 \mathrm{D})$. The red $\square$ represents postoperative refractive astigmatism. The pink star represents the mean postoperative astigmatism vector $(-0.92 \pm 0.72, P<0.001)$. The mean astigmatism vector is brought closer to the null position after surgery, and the standard deviation is reduction 